\title{
Effect of Titanium Addition on the Thermal Properties of Diamond/Cu-Ti Composites Fabricated by Pressureless Liquid-Phase Sintering Technique
}

\author{
Chih-Yu Chung, Chao-Hung Chu, Mu-Tse Lee, Chun-Ming Lin, and Su-Jien Lin \\ Department of Materials Science and Engineering, National Tsing Hua University, Hsinchu 30013, Taiwan \\ Correspondence should be addressed to Su-Jien Lin; sjlin@mx.nthu.edu.tw
}

Received 7 November 2013; Accepted 28 January 2014; Published 4 March 2014

Academic Editors: Q. Fu and F. Oktar

Copyright (c) 2014 Chih-Yu Chung et al. This is an open access article distributed under the Creative Commons Attribution License, which permits unrestricted use, distribution, and reproduction in any medium, provided the original work is properly cited.

In this study, minor-addition elements such as $\mathrm{Si}, \mathrm{Co}, \mathrm{Cr}, \mathrm{W}, \mathrm{Mo}$, and $\mathrm{Ti}$ were added to matrix to improve the wettability between the diamonds and $\mathrm{Cu}$ matrix. The pressureless liquid-phase sintering technique adopted in this study provides a low-cost method for producing diamond/Cu composites with high potential for industrial mass production. Thermal properties of the diamond/Cu-Ti composites fabricated by pressureless liquid-phase sintering at $1373 \mathrm{~K}$ with variation in Ti contents were thoroughly investigated. $\mathrm{XRD}$ and TEM analysis show that TiC layer formed in the interface between $\mathrm{Cu}$ and diamond. The composites exhibited thermal conductivity as high as $620 \mathrm{~W} / \mathrm{m} \cdot \mathrm{K}$ for $50 \mathrm{vol} \%$ diamond/Cu- 0.6 at \% Ti composite with diamond particle size of $300 \mu \mathrm{m}$. This value comes up to $85 \%$ of the thermal conductivity calculated by the Hasselman and Johnson (H-J) theoretical analysis. Under these conditions, a suitable coefficient of thermal expansion of $6.9 \mathrm{ppm} / \mathrm{K}$ was obtained.

\section{Introduction}

Conventional thermal management materials with thermal conductivities (above $200 \mathrm{~W} / \mathrm{m} \cdot \mathrm{K}$ ) and coefficients of thermal expansion ( $4-8 \mathrm{ppm} / \mathrm{K})$ were summarized by Zweben [1]. However, owing to the increase in device power and integration levels [2], the demand for novel thermal management materials with high thermal conductivities is on the rise.

Due to their excellent thermal properties, synthetic diamonds with high thermal conductivity $(1200-2000 \mathrm{~W} / \mathrm{m} \cdot \mathrm{K})$ are the most attractive thermal spreading material. However, diamond films utilized to spread heat are too thin to spread efficiently and it is very difficult to form bulk synthetic diamond. Therefore, high thermal conductive metals, such as $\mathrm{Al}, \mathrm{Ag}$, and $\mathrm{Cu}$, were utilized as binders to form bulk composites [3-7] reinforced with diamond to match this demand. However, due to the poor wettability between diamond and metal, the interfaces between diamond and metal are not in well contact and this will be detrimental for heat conduction between the interfaces. There are two alternative methods to improve the contact between diamond and metal. The first method is to fabricate composites under high pressure (above $1 \mathrm{GPa}$ ) and high temperature (above the melting point of metal) process conditions which requires expensive and complex equipment [8]. The second method can be achieved through carbide-forming elements addition to form a thin carbide layer at the interface and to improve the contact and wettability between diamond and metal [9-16].

In recent years, high thermal conductive diamond/metal composites used as heat sink have been fabricated by various techniques with high pressure, expensive, and complex equipment, such as hot pressing [17], gas pressure infiltration [18-20], and spark plasma sintering [21]. In this study, diamond/Cu composites were fabricated by pressureless liquid-phase sintering technique with minor-addition elements to improve the contact and wettability between the diamond and Cu matrix. The results in this study demonstrate that pressureless liquid-phase sintering technique is a very promising process for fabricating diamond/Cu-Ti composites with the potential for mass production.

\section{Materials and Methods}

Saw diamond powders with thermal conductivity of $1800 \mathrm{~W} / \mathrm{m} \cdot \mathrm{K}$ and a particle size of $300 \mu \mathrm{m}(\mathrm{YK}-9 \mathrm{E}$, Fine 
Abrasives Taiwan Company) were used as reinforcements. $\mathrm{Cu}$ powders with thermal conductivity of $400 \mathrm{~W} / \mathrm{m} \cdot \mathrm{K}$ and with a particle size of $5 \mu \mathrm{m}$ (purity in $99.9 \mathrm{wt} \%$, Artc-1000 A, Advance Research Technology Corporation) and minoraddition element powders ( $\mathrm{Si}, \mathrm{Co}, \mathrm{Cr}, \mathrm{W}, \mathrm{Mo}$, and $\mathrm{Ti}$ ) with a particle size of $100 \mu \mathrm{m}$ (purity in $99.9 \mathrm{wt} \%$, Alfa Aesar) were mixed as matrix materials.

Diamond, copper, and minor-addition element powders were mechanically mixed and compacted under $700 \mathrm{MPa}$ for 10 minutes to fabricate diamond/Cu composites with a diameter of $12.9 \mathrm{~mm}$ and height of $3 \mathrm{~mm}$ and then sintered in tube furnace with $\mathrm{H}_{2}(100 \mathrm{sccm})$ gas flow under vacuum (1.8 torr) at $1373 \mathrm{~K}$ for 30 minutes.

Micrographs and element compositions of diamond/CuTi composites were analyzed by a scanning electron microscope (SEM, JEOL-5410) and an X-ray diffractometer (XRD, Rigaku_D/DMAXIIB). Thermal conductivity was measured via laser-flash analyzer (LFA, Netzsch-LFA 447). Coefficient of thermal expansion (CTE) was measured by thermal analysis apparatus (TMA, Seiko-SSC5200) with a heating rate of $3 \mathrm{~K} / \mathrm{min}$, ranging from $373 \mathrm{~K}$ to $473 \mathrm{~K}$. The Archimedes method was applied to measure the densities of the composites and the relative densities were obtained by comparing measured densities with the theoretical densities. Focused ion beam (FIB, FEI-Nova 200) technology was used for the preparation of transmission electron microscope (TEM, JEOL-JEM3000F) samples. The samples were then observed under TEM to reveal the boundary regions of the diamond/Cu interface.

\section{Results and Discussion}

3.1. Diamond/Cu Composites with Varying Minor-Addition Elements. The sample images of $50 \mathrm{vol} \%$ diamond/Cu composites with 3 at \% varying minor-addition elements are shown in Figure 1. It can be seen that only W, Mo, and $\mathrm{Ti}$ addition can form integral-shape composites without matrix repelling from the composites. Of all the chosen minoraddition elements, W, Mo, and Ti all belong to the carbideforming elements. The other minor-addition elements added to the composites are incapable of forming integral-shape composites due to matrix repelling from the composites during the sintering process.

Figure 2 shows the surface SEM images of the 50 vol\% diamond/Cu composites with 3 at \% (a) W, (b) Mo, and (c) $\mathrm{Ti}$ additions. Figures 2(a) and 2(b) show apparent interfacial pores at the boundaries between the diamonds and $\mathrm{Cu}$ matrix. It is considered that $\mathrm{W}$ and Mo additions can form integral-shape composites but cannot improve the contact between the diamonds and $\mathrm{Cu}$ matrix efficiently. In Figure 2(c), it can be seen that the diamonds and $\mathrm{Cu}$ matrix are in well contact at the boundaries and the $\mathrm{Cu}$ matrix can cover the diamond surfaces entirely. Furthermore, the thermal conductivities of the composites are 209, 257, and $348 \mathrm{~W} / \mathrm{m} \cdot \mathrm{K}$ for 3 at $\% \mathrm{~W}, \mathrm{Mo}$, and $\mathrm{Ti}$ additions, respectively. The highest value of thermal conductivity was obtained with $\mathrm{Ti}$ addition in this study. Therefore, $\mathrm{Ti}$ is regarded as the most suitable carbide-forming element in this study to improve the contact and wettability at the boundaries between the diamonds and $\mathrm{Cu}$ matrix.

3.2. Microstructure and Composition Analysis of Diamond/CuTi Composites. The sample images of the $50 \mathrm{vol} \%$ diamond composites with varying $\mathrm{Ti}$ addition $(0.2,0.3$, and 0.6 at \%) in the $\mathrm{Cu}$ matrix are shown in Figure 3. It can be seen that the addition of 0.2 at $\% \mathrm{Ti}$ (Figure $3(\mathrm{a})$ ) is not enough to form an integral-shape composite without matrix repelling. The integral-shape composites can be achieved only above 0.3 at $\% \mathrm{Ti}$ addition. Composite with 0.6 at \% $\mathrm{Ti}$ addition has a good integral-shape as shown in Figure 3(c).

Figure 4 shows the surface SEM images of the 50 vol\% diamond composites with varying $\mathrm{Ti}$ addition in the $\mathrm{Cu}$ matrix. Figure 4(a) shows apparent interfacial pores at the boundary between the diamonds and the matrix appearing in $\mathrm{Cu}-0.3$ at \% Ti composites. With increasing Ti content, fewer interfacial pores were found in the contact regions between the diamonds and the $\mathrm{Cu}$ matrix. When the $\mathrm{Ti}$ content increased to 0.6 and 0.9 a $\mathrm{t} \%$, there were no apparent interfacial pores and the diamond surface was entirely covered by the copper matrix as shown in Figures 4(c) and 4(d). These phenomena indicate that increasing Ti content improves the wettability and contact between $\mathrm{Cu}$ matrix and diamond surface effectively, and therefore less interfacial pores were produced during the process.

The X-ray diffraction patterns of the diamond/Cu-Ti composites, shown in Figure 5, indicate that the peaks only belonged to diamond, $\mathrm{Cu}$, and $\mathrm{TiC}$. It can be deduced that $\mathrm{TiC}$ forms during the sintering process. The peak intensity grows stronger with increasing Ti content, indicating greater amount of $\mathrm{TiC}$ formation.

Figure 6 shows the TEM bright field image and EDS interface line-scan signals of a 50 vol $\%$ diamond/Cu-0.6 at $\% \mathrm{Ti}$ composite interface. The interface between $\mathrm{Cu}$ matrix and diamond is composed of a columnar structure near $\mathrm{Cu}$ and an irregular layer near diamond. The $\mathrm{C}, \mathrm{Ti}$, and $\mathrm{Cu}$ EDS line scans were used to determine the distribution of element across the interface, as shown in Figure 6. It is clear that the scan path consists of four zones: (a) $\mathrm{Cu}$ matrix region, (b) Ti-rich columnar region, (c) $\mathrm{Cu}-\mathrm{C}$ irregular region, and (d) diamond region. The insert in Figure 6 is the diffraction pattern of circle region in Ti-rich columnar structure and indicates that this columnar structure is a $\mathrm{TiC}$ crystal structure. This is consistent with the X-ray diffraction analysis as shown in Figure 5. This columnar TiC layer is about $270 \mathrm{~nm}$ in thickness. The $\mathrm{Cu}-\mathrm{C}$ irregular layer is comprised of $\mathrm{Cu}$ and $\mathrm{C}$ which may have resulted from the reaction during sintering. The structure of this irregular layer is composed of $\mathrm{Cu}$ and $\mathrm{C}$. However, the mechanism for the formation of this interfacial structure still requires further investigation.

\subsection{Thermal Conductivity and Coefficient of Thermal Expan-} sion (CTE). Figure 7 shows the curves of relative density, thermal conductivity, and coefficient of thermal expansion versus Ti content with (a) 50 vol\% diamond and (b) 60 vol\% diamond. It can be seen that the relative densities decrease with increasing diamond volume fraction, due to the increase 


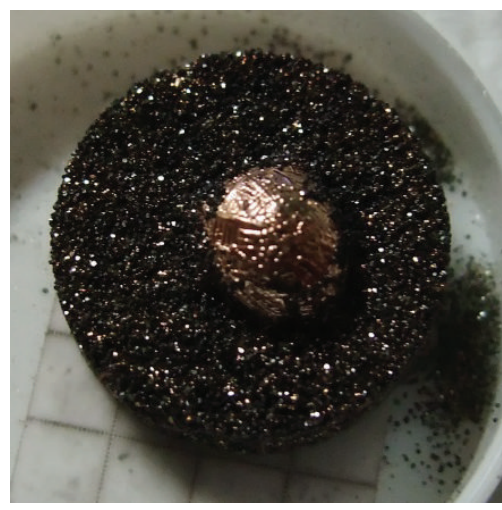

(a)

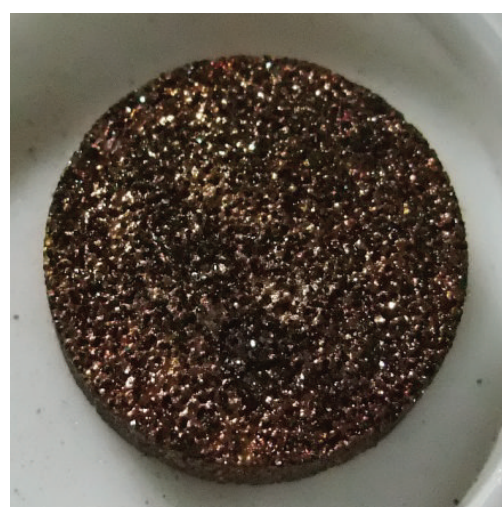

(d)

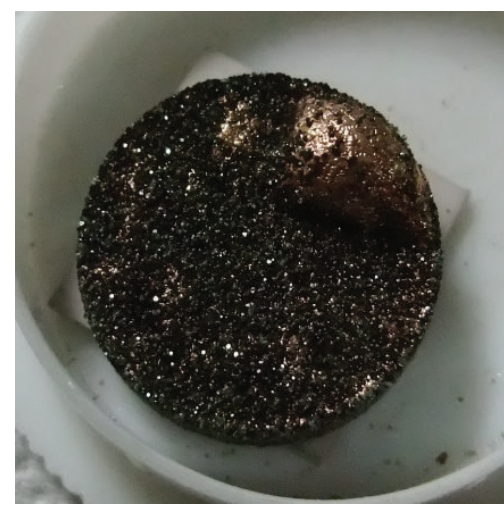

(b)

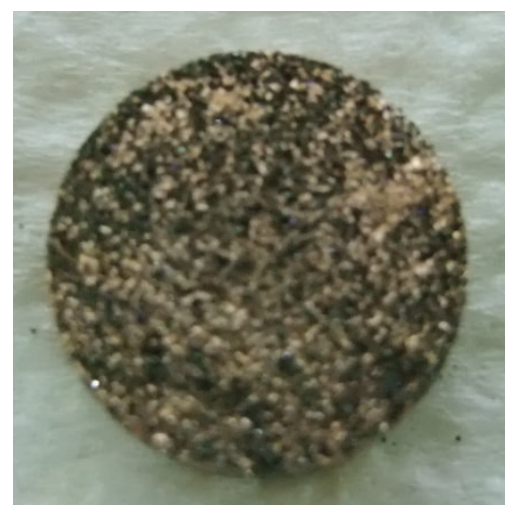

(e)

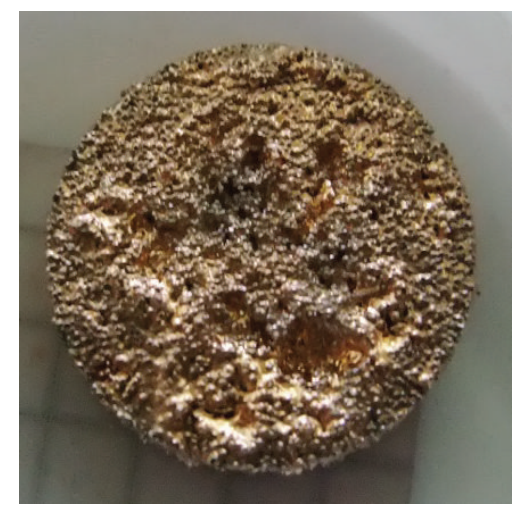

(c)

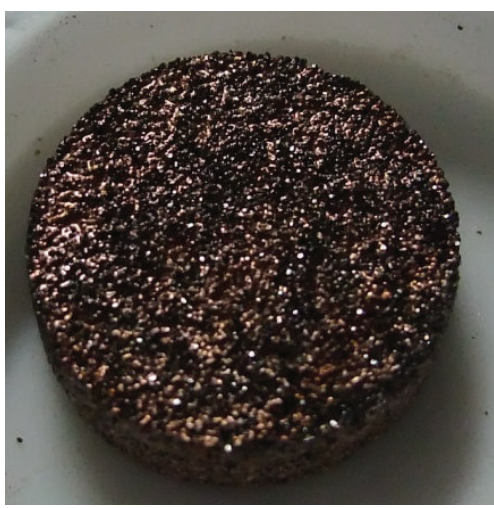

(f)

Figure 1: The sample images of 50 vol\% diamond/Cu composites with 3 at \% varying minor-elements addition: (a) $\mathrm{Si}$, (b) Co, (c) Cr, (d) W, (e) Mo, and (f) Ti.

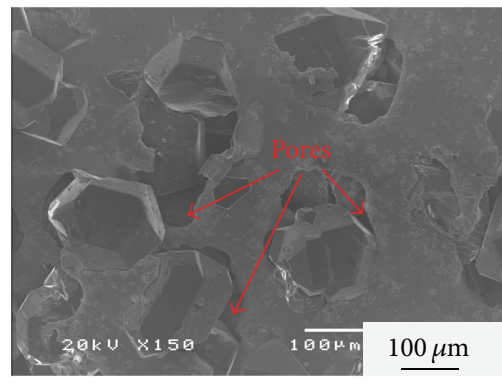

(a)

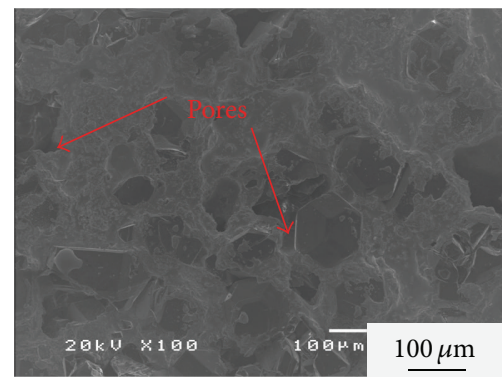

(b)

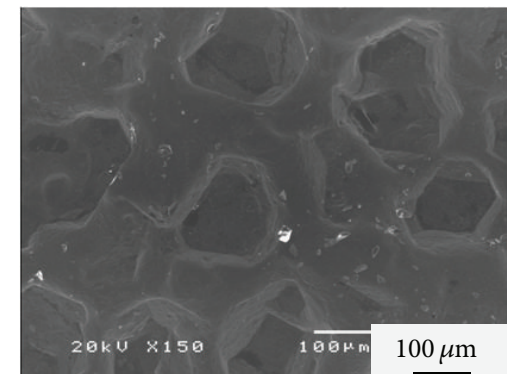

(c)

Figure 2: The surface SEM images of the 50 vol\% diamond/Cu composites with (a) 3 at \% W addition, (b) 3 at $\%$ Mo addition, and (c) 3 at $\%$ Ti addition.

in interfacial areas and the more bridging effect between diamonds.

Figure 7 indicates that initially the thermal conductivity values increase with increasing $\mathrm{Ti}$ addition, upon reaching a maximum, and then the thermal conductivities begin to show apparent decrease with further addition. The $\mathrm{Ti}$ addition enhanced the wettability between diamond and $\mathrm{Cu}$, thus promoting the interfacial contact between the matrix and diamond during pressureless liquid-phase sintering and increasing the thermal conductivities of the composites.
Thermal conductivity of the highest $620 \mathrm{~W} / \mathrm{m} \cdot \mathrm{K}$ value can be achieved for 50 vol $\%$ diamond/Cu- 0.6 at $\%$ Ti composite. However, upon exceeding 0.7 at $\% \mathrm{Ti}$ addition, the thermal conductivity decreases drastically.

It is considered that varying amounts of diamond surface areas need varying $\mathrm{Ti}$ addition to improve the wettability of the interface and then have the highest thermal conductivity in each diamond volume fraction condition. By assuming diamonds as spheres with a diameter of $300 \mu \mathrm{m}$ for simplified calculation, the diamond surface areas of the $50 \mathrm{vol} \%$ 


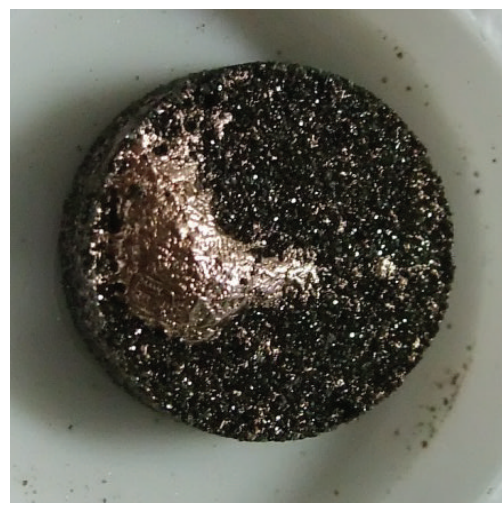

(a)

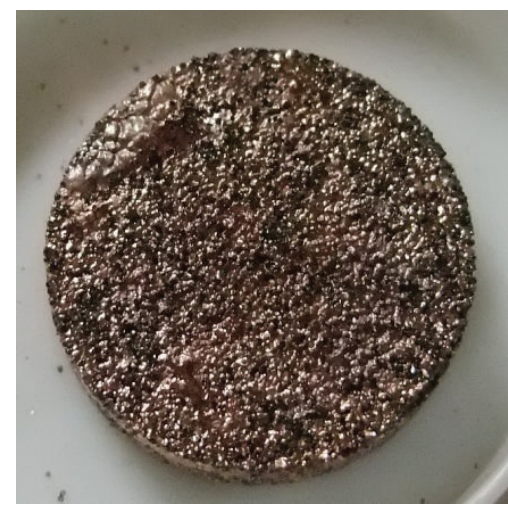

(b)

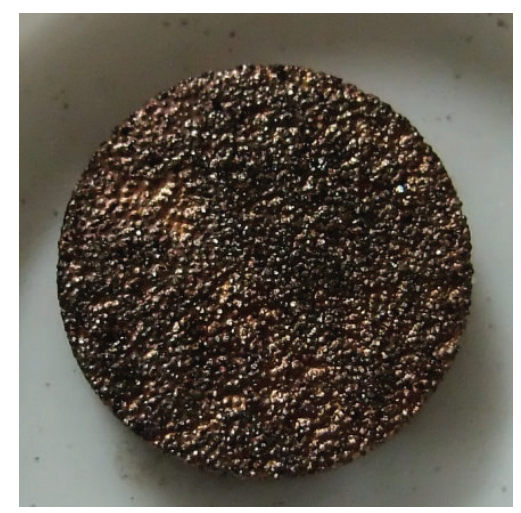

(c)

Figure 3: The sample images of the 50 vol\% diamond composites with varying Ti addition in the $\mathrm{Cu}$ matrix: (a) 0.2 at $\% \mathrm{Ti}$, (b) 0.3 at $\% \mathrm{Ti}$, and (c) 0.6 at $\% \mathrm{Ti}$.

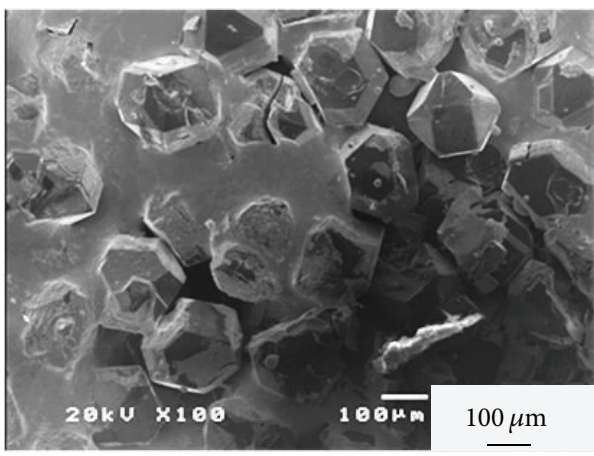

(a)

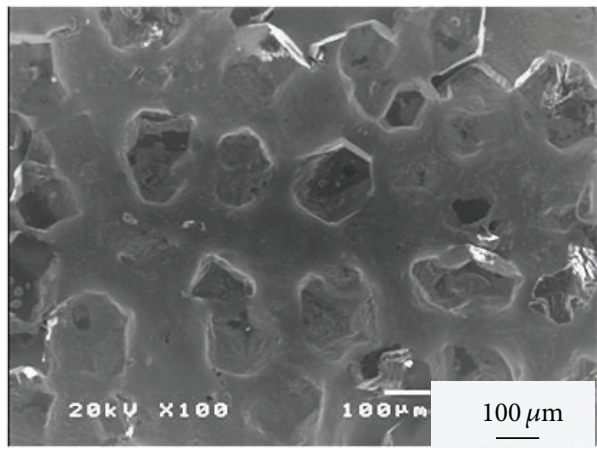

(c)

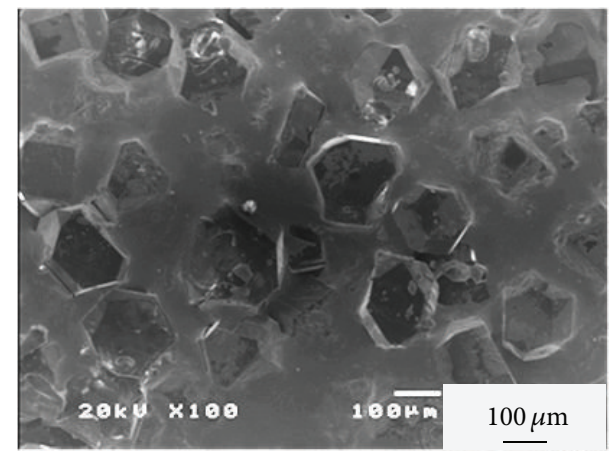

(b)

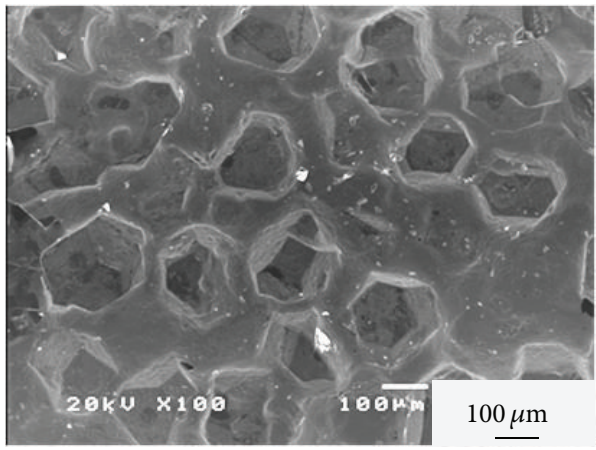

(d)

Figure 4: The surface SEM images of the 50 vol\% diamond composites with varying Ti addition in the Cu matrix: (a) 0.3 at \% Ti, (b) 0.4 at $\% \mathrm{Ti},(\mathrm{c}) 0.6$ at $\% \mathrm{Ti}$, and (d) 0.9 at $\% \mathrm{Ti}$.

condition (the volume of the composite is $3.92 \times 10^{-7} \mathrm{~m}^{3}$ ) are $3.92 \times 10^{-3} \mathrm{~m}^{2}$ and $60 \mathrm{vol} \%$ condition (the volume of the composite is $3.92 \times 10^{-7} \mathrm{~m}^{3}$ ) is $4.7 \times 10^{-3} \mathrm{~m}^{2}$. Considering that the highest thermal conductivity of $50 \mathrm{vol} \%$ condition is obtained with 0.6 at \% Ti addition and comparing the surface areas values of $50 \mathrm{vol} \%$ and $60 \mathrm{vol} \%$, it can be calculated that the optimum Ti addition in $60 \mathrm{vol} \%$ condition is 0.92 at $\%$. The experimental results verify this calculation, as shown in Figure 7(b). The 60 vol\% diamond composites exhibit the highest thermal conductivity up to $579 \mathrm{~W} / \mathrm{m} \cdot \mathrm{K}$ with 0.92 at $\%$
Ti content. However, upon exceeding this optimum 0.92 at $\%$ Ti addition, the thermal conductivity decreases drastically as the trend in the $50 \mathrm{vol} \%$ diamond composites.

The above results indicate that suitable Ti addition and TiC thickness strengthen the interfacial bonding to improve thermal conductivity. However, the thermal conductivities of the composites later decreased owing to the excess formation of the TiC interphase (Figure 6) with low thermal conductivity during the sintering process. Thermal conductivities of $60 \mathrm{vol} \%$ diamond composites are lower than those of $50 \mathrm{vol} \%$ 


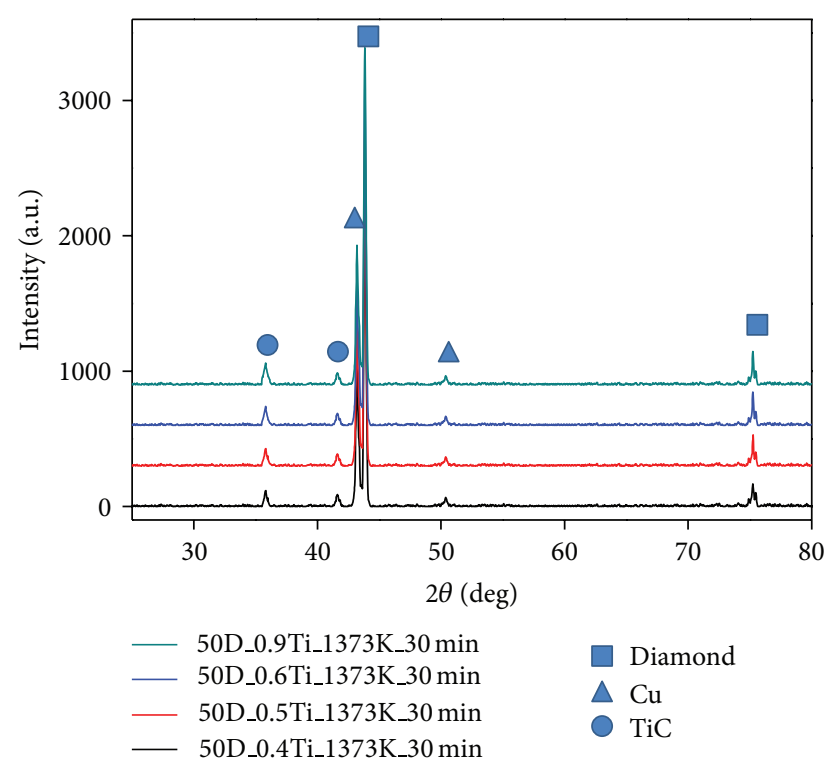

Figure 5: The X-ray diffraction patterns of the 50 vol\% diamond/Cu-Ti composites with varying Ti content.

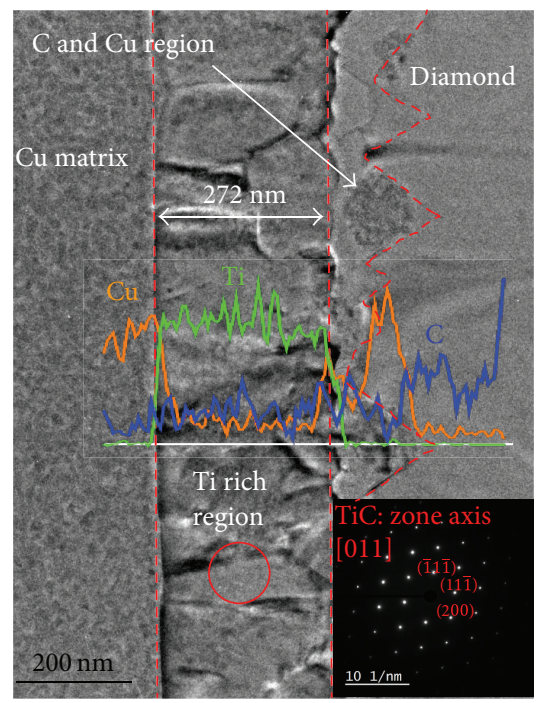

FIGURE 6: TEM bright field image and EDS interface line-scan signals of a $50 \mathrm{vol} \%$ diamond $/ \mathrm{Cu}-0.6$ at $\% \mathrm{Ti}$ composite interface. The insert is the diffraction pattern of columnar structure (red circle region).

diamond composites. These can be attributed to lower relative densities of the composite under $60 \mathrm{vol} \%$ conditions. It is considered that the suitable Ti addition in each diamond volume fraction condition is proportional to the amounts of diamond surface areas.

The CTE values in this study are in the range of 5 to $8 \mathrm{ppm} / \mathrm{K}$, which are the adequate values for thermal management materials that are to be utilized in electronic devices [1]. The CTE values of the composites decrease monotonously from 7.7 to $6.5 \mathrm{ppm} / \mathrm{K}$ (for composites with a diamond content of 50 vol\% and $0.3-0.9$ at $\% \mathrm{Ti}$ ) or from
5.9 to $5.1 \mathrm{ppm} / \mathrm{K}$ (for composites with a diamond content of $60 \mathrm{vol} \%$ and $0.52-1.02 \mathrm{at} \% \mathrm{Ti}$ ) with increasing $\mathrm{Ti}$ content. This can be explained by the improvement in bonding at the interface with higher content of Ti addition. The CTE values of $60 \mathrm{vol} \%$ diamond composites are lower than those of $50 \mathrm{vol} \%$. This is due to the fact that the low CTE value of diamonds $(1.3 \mathrm{ppm} / \mathrm{K})$ provides greater contribution to the CTE values of composites comprised of higher diamond content, thus reducing the final CTE value outcomes of the composites.

In recent years, high thermal conductive $\mathrm{Cu} /$ diamond composites with thermal conductivities of $700,657,493$, and $615 \mathrm{~W} / \mathrm{m} \cdot \mathrm{K}$ fabricated by high-cost techniques have been published. The composites produced in this study demonstrate thermal conductivities comparable with findings in previous literature made by other authors [18, 21-23]. However, in comparison with these techniques, the fabrication technique applied in this study provides a low-cost, simple alternative to fabricate diamond/Cu composites with great potential for industrial mass production.

3.4. Theoretical Analysis of Thermal Conductivity. In order to fully understand the thermal conduction behavior in diamond/Cu-Ti composites, it is crucial to compare the experimental results with theoretical predictions. The Hasselman and Johnson (H-J) model applied in combination with effective medium approximation (EMA) scheme is the most popular predictive method, in which the Kapitza resistance effect and particle size are taken into consideration [23]:

$$
K_{c}=\frac{K_{m}\left[2 K_{m}+K_{p}^{\mathrm{efff}}+2\left(K_{p}^{\mathrm{eff}}-K_{m}\right) V_{p}\right]}{2 K_{m}+K_{p}^{\mathrm{eff}}-\left(K_{p}^{\mathrm{eff}}-K_{m}\right) V_{p}},
$$

where $K$ is the thermal conductivity, $V$ is the volume fraction of reinforcement, and the subscripts $c, m$, and $p$ refer to the composite, matrix, and reinforcement particles, respectively. The effective thermal conductivity of reinforcement particles, $K_{p}^{\mathrm{eff}}$, is defined as [23]:

$$
K_{p}^{\mathrm{eff}}=\frac{K_{p}}{1+2 R_{k} K_{p} / d},
$$

where $d$ is the average diameter of reinforcements and $R_{k}$ is the interfacial resistance (Kapitza resistance). However, the model was made under the assumption that the interface between the matrix and reinforcements is perfect and sharp $[23,24]$. In the case of this study, interphases formed at the interface, which contributed additional thermal resistance to the initially assumed diamond/metal sharp interface. To obtain an accurate model for thermal conductivity prediction, the thermal resistance of the interphases should be considered. In order to simplify the calculation, the $\mathrm{Cu}-\mathrm{Ti}$ $\mathrm{C}$ irregular layer is still neglected. The interfacial thermal resistance can be expressed by

$$
\begin{gathered}
R_{k}=R_{\mathrm{Cu} / \mathrm{TiC}}+R_{\mathrm{TiC}}+R_{\mathrm{TiC} / \text { Diamond, }} \\
R_{\mathrm{TiC}}=\frac{\text { thickness of } \mathrm{TiC}}{K_{\mathrm{TiC}}}
\end{gathered}
$$




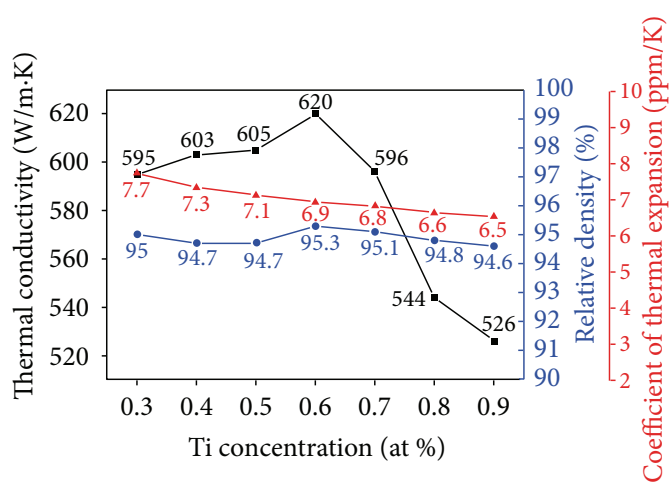

(a)

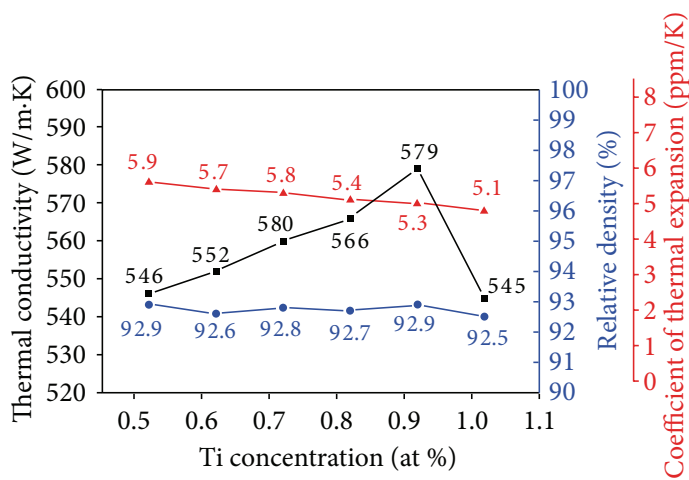

(b)

Figure 7: The curves of thermal conductivity, relative density, and coefficient of thermal expansion versus Ti content with (a) 50 vol\% diamond and (b) 60 vol\% diamond.

TABLE 1: The longitudinal, transverse phonon velocity and thermal conductivity of $\mathrm{Cu}, \mathrm{TiC}$, and diamond in theoretical calculation [24, 25].

\begin{tabular}{lccc}
\hline Materials & $\begin{array}{c}\text { Phonon velocity } \\
v_{\text {longitudinal }}\left(\times 10^{3} \mathrm{~m} / \mathrm{s}\right)\end{array}$ & $\begin{array}{c}\text { Phonon velocity } \\
v_{\text {transverse }}\left(\times 10^{3} \mathrm{~m} / \mathrm{s}\right)\end{array}$ & $\begin{array}{c}\text { Thermal conductivity } \\
K(\mathrm{~W} / \mathrm{m} \cdot \mathrm{K})\end{array}$ \\
\hline $\mathrm{Cu}$ & 4.8 & 2.3 & 380 \\
$\mathrm{TiC}$ & 10.1 & 7.3 & 19 \\
Diamond & 17.5 & 12.8 & 1800 \\
\hline
\end{tabular}

where $R_{\mathrm{Cu} / \mathrm{TiC}}, R_{\mathrm{TiC}}$, and $R_{\mathrm{TiC} / \text { Diamond }}$ are the thermal resistance of $\mathrm{Cu} / \mathrm{TiC}$ interface, $\mathrm{TiC}$ interphase, and $\mathrm{TiC} /$ Diamond interface, respectively, and $K_{\mathrm{TiC}}$ is the thermal conductivity of TiC.

The thermal resistance, $R_{\mathrm{Cu} / \mathrm{TiC}}$ and $R_{\mathrm{TiC} / \text { Diamond }}$, can be described by diffuse mismatch model (DMM). This interphase thermal resistance, $R_{i / 3-i}$, based on DMM model is related to the phonon velocities $(v)$ in the $i$ phase and the 3-i phase, as well as the absolute temperature $T$, can be expressed in the following form [23]:

$$
R_{i / 3-i}=\left[1.02 \times 10^{10} \frac{\left(\sum_{j} v_{i, j}^{-2}\right)\left(\sum_{j} v_{3-i, j}^{-2}\right)}{\sum_{i, j} v_{i, j}^{-2}}\right]^{-1} \times T^{-3},
$$

where the subscripts $i$ and 3-i refer to the two adjacent phases on each side of the interface. The subscript $j$ represents the mode of phonon velocity (longitudinal or transverse).

In this modeling, the effect of porosity was taken into account by reassigning an effective thermal conductivity to the composite. The effective thermal conductivity of the composite was derived from combining the thermal conductivity of composite and air according to the rule of mixture (ROM):

$$
K_{c-p}=K_{c} \times V_{c}+K_{\text {air }} \times V_{\text {porosity }}
$$

where $K_{c-p}$ represents the thermal conductivity of composites containing pores. $K_{c}$ is the result of thermal conductivity of the composite calculated by (1)-(4). $V_{c}$ and $V_{\text {porosity }}$ are the volume fraction of composite and porosity, respectively.
Table 1 shows the longitudinal, transverse phonon velocities $[24,25]$ and thermal conductivities of $\mathrm{Cu}, \mathrm{TiC}$, and diamond in theoretical values. Combining the above equations (1)-(5) and theoretical values, the values of the interfacial resistance and theoretical thermal conductivity can be calculated as shown in Table 2.

The calculated theoretical thermal conductivity is $725 \mathrm{~W} / \mathrm{m} \cdot \mathrm{K}$ and the experimental value is $620 \mathrm{~W} / \mathrm{m} \cdot \mathrm{K}$ as shown in Table 2 and Figure 7(a), respectively. It appears that the experimental value comes up to $85 \%$ of the theoretical value. The good comparison results between the theoretical analysis and experimental measurements support the feasibility of incorporating the consideration of additional interfacial thermal resistance effect caused by the interphase into H-J model.

\section{Conclusions}

Diamond/Cu-Ti composites with high thermal conductivities can be successfully fabricated via pressureless liquid-phase sintering method. XRD and TEM analysis show that the $\mathrm{TiC}$ layer formed at the interface between $\mathrm{Cu}$ and diamond. Under the condition of $50 \mathrm{vol} \%$ diamond $/ \mathrm{Cu}-0.6$ at $\% \mathrm{Ti}$, the composite shows the highest value of thermal conductivity of $620 \mathrm{~W} / \mathrm{m} \cdot \mathrm{K}$ and a low CTE value of $6.9 \mathrm{ppm} / \mathrm{K}$, which comes up to $85 \%$ of the thermal conductivity calculated by the Hasselman and Johnson (H-J) theoretical analysis. Applying pressureless liquid-phase sintering method to fabricate high thermal conductive composites provides an easy and 
TABLE 2: The calculation values of the interfacial resistance and theoretical thermal conductivity of the 50 vol $\%$ diamond/Cu- 0.6 at $\%$ Ti composite.

\begin{tabular}{lcccccc}
\hline$R_{\text {TiC/diamond }}\left(\mathrm{m}^{2} \cdot \mathrm{K} / \mathrm{W}\right)$ & $R_{\mathrm{TiC}}\left(\mathrm{m}^{2} \cdot \mathrm{K} / \mathrm{W}\right)$ & $R_{\mathrm{Cu} / \mathrm{TiC}}\left(\mathrm{m}^{2} \cdot \mathrm{K} / \mathrm{W}\right)$ & $R_{k}\left(\mathrm{~m}^{2} \cdot \mathrm{K} / \mathrm{W}\right)$ & $K_{p}^{\mathrm{eff}}(\mathrm{W} / \mathrm{m} \cdot \mathrm{K})$ & $K_{c}(\mathrm{~W} / \mathrm{m} \cdot \mathrm{K})$ & $K_{c-p}(\mathrm{~W} / \mathrm{m} \cdot \mathrm{K})$ \\
\hline $5.2 \times 10^{-10}$ & $1.4 \times 10^{-8}$ & $1.4 \times 10^{-10}$ & $1.5 \times 10^{-8}$ & 1530 & 761 & 725 \\
\hline
\end{tabular}

cost-effective alternative method to produce diamond/Cu$\mathrm{Ti}$ composites with high thermal conductivities for thermal management applications.

\section{Conflict of Interests}

The authors declare that there is no conflict of interests regarding the publication of this paper.

\section{Acknowledgment}

The authors would like to thank the National Science Council, Taiwan, for supporting this research through Project no. NSC-102-2221-E-007-046-MY3.

\section{References}

[1] C. Zweben, "Advanced materials for optoelectronic packaging," Electronic Packaging and Production, vol. 42, no. 9, pp. 37-40, 2002.

[2] D. B. Miracle, "Metal matrix composites-from science to technological significance," Composites Science and Technology, vol. 65, no. 15-16, pp. 2526-2540, 2005.

[3] J. H. Wu, H. L. Zhang, Y. Zhang, J. W. Li, and X. T. Wang, "Effect of copper content on the thermal conductivity and thermal expansion of $\mathrm{Al}-\mathrm{Cu} /$ diamond composites," Materials and Design, vol. 39, pp. 87-92, 2012.

[4] W. B. Johnson and B. Sonuparlak, "Diamond/Al metal matrix composites formed by the pressureless metal infiltration process," Journal of Materials Research, vol. 8, no. 5, pp. 1169-1173, 1993.

[5] K. Hanada, K. Matsuzaki, and T. Sano, "Thermal properties of diamond particle-dispersed Cu composites," Journal of Materials Processing Technology, vol. 153-154, no. 1-3, pp. 514-518, 2004.

[6] O. Beffort, F. A. Khalid, L. Weber et al., "Interface formation in infiltrated $\mathrm{Al}(\mathrm{Si}) /$ diamond composites," Diamond and Related Materials, vol. 15, no. 9, pp. 1250-1260, 2006.

[7] R. Tavangar, J. M. Molina, and L. Weber, "Assessing predictive schemes for thermal conductivity against diamond-reinforced silver matrix composites at intermediate phase contrast," Scripta Materialia, vol. 56, no. 5, pp. 357-360, 2007.

[8] K. Yoshida and H. Morigami, "Thermal properties of diamond/copper composite material," Microelectronics Reliability, vol. 44, no. 2, pp. 303-308, 2004.

[9] Z. Q. Tan, Z. Q. Li, G. L. Fan et al., "Enhanced thermal conductivity in diamond/aluminum composites with a tungsten interface nanolayer," Materials and Design, vol. 47, pp. 160-166, 2013.

[10] P. Xiao and B. Derby, "Wetting of titanium nitride and titanium carbide by liquid metals," Acta Materialia, vol. 44, no. 1, pp. 307314, 1996.

[11] A. M. Abyzov, S. V. Kidalov, and F. M. Shakhov, "High thermal conductivity composites consisting of diamond filler with tungsten coating and copper (silver) matrix," Journal of Materials Science, vol. 46, no. 5, pp. 1424-1438, 2011.

[12] T. Schubert, B. Trindade, T. Weißgärber, and B. Kieback, "Interfacial design of Cu-based composites prepared by powder metallurgy for heat sink applications," Materials Science and Engineering A, vol. 475, no. 1-2, pp. 39-44, 2008.

[13] H. Bai, N. G. Ma, J. Lang, and C. X. Zhu, "Effect of a new pretreatment on the microstructure and thermal conductivity of $\mathrm{Cu}$ /diamond composites," Journal of Alloys and Compounds, vol. 580, pp. 382-385, 2013.

[14] Q. P. Kang, X. B. He, S. B. Ren et al., "Effect of molybdenum carbide intermediate layers on thermal properties of copperdiamond composites," Journal of Alloys and Compounds, vol. 576, pp. 380-385, 2013.

[15] X. Y. Shen, X. B. He, S. B. Ren, H. M. Zhang, and X. H. Qu, "Effect of molybdenum as interfacial element on the thermal conductivity of diamond/Cu composites," Journal of Alloys and Compounds, vol. 529, pp. 134-139, 2012.

[16] K. Chu, Z. Liu, C. Jia et al., "Thermal conductivity of SPS consolidated $\mathrm{Cu}$ /diamond composites with Cr-coated diamond particles," Journal of Alloys and Compounds, vol. 490, no. 1-2, pp. 453-458, 2010.

[17] B. B. Liu, J. X. Xie, and X. H. Qu, "Fabrication of W-Cu functionally graded materials with high density by particle size adjustment and solid state hot press," Composites Science and Technology, vol. 68, no. 6, pp. 1539-1547, 2008.

[18] L. Weber and R. Tavangar, "On the influence of active element content on the thermal conductivity and thermal expansion of $\mathrm{Cu}-\mathrm{X}(\mathrm{X}=\mathrm{Cr}, \mathrm{B})$ diamond composites," Scripta Materialia, vol. 57, no. 11, pp. 988-991, 2007.

[19] I. E. Monje, E. Louis, and J. M. Molina, "Optimizing thermal conductivity in gas-pressure infiltrated aluminum/diamond composites by precise processing control," Composites A, vol. 48, pp. 9-14, 2013.

[20] P. W. Ruch, O. Beffort, S. Kleiner, L. Weber, and P. J. Uggowitzer, "Selective interfacial bonding in $\mathrm{Al}(\mathrm{Si})$-diamond composites and its effect on thermal conductivity," Composites Science and Technology, vol. 66, no. 15, pp. 2677-2685, 2006.

[21] S. Ren, X. Shen, C. Guo et al., "Effect of coating on the microstructure and thermal conductivities of diamond-Cu composites prepared by powder metallurgy," Composites Science and Technology, vol. 71, no. 13, pp. 1550-1555, 2011.

[22] Y. Zhang, H. L. Zhang, J. H. Wu, and X. T. Wang, "Enhanced thermal conductivity in copper matrix composites reinforced with titanium-coated diamond particles," Scripta Materialia, vol. 65, no. 12, pp. 1097-1100, 2011.

[23] K. Chu, C. C. Jia, H. Guo, and W. S. Li, "On the thermal conductivity of $\mathrm{Cu}-\mathrm{Zr} /$ diamond composites," Materials and Design, vol. 45, pp. 36-42, 2013.

[24] E. T. Swartz and R. O. Pohl, "Thermal boundary resistance," Reviews of Modern Physics, vol. 61, no. 3, pp. 605-668, 1989.

[25] B. Klein, N. Frage, E. Zaretsky, and M. P. Dariel, "Dynamic response of titanium carbide-steel, ceramic-metal composites," AIP Conference Proceedings, vol. 620, pp. 1119-1122, 2002. 

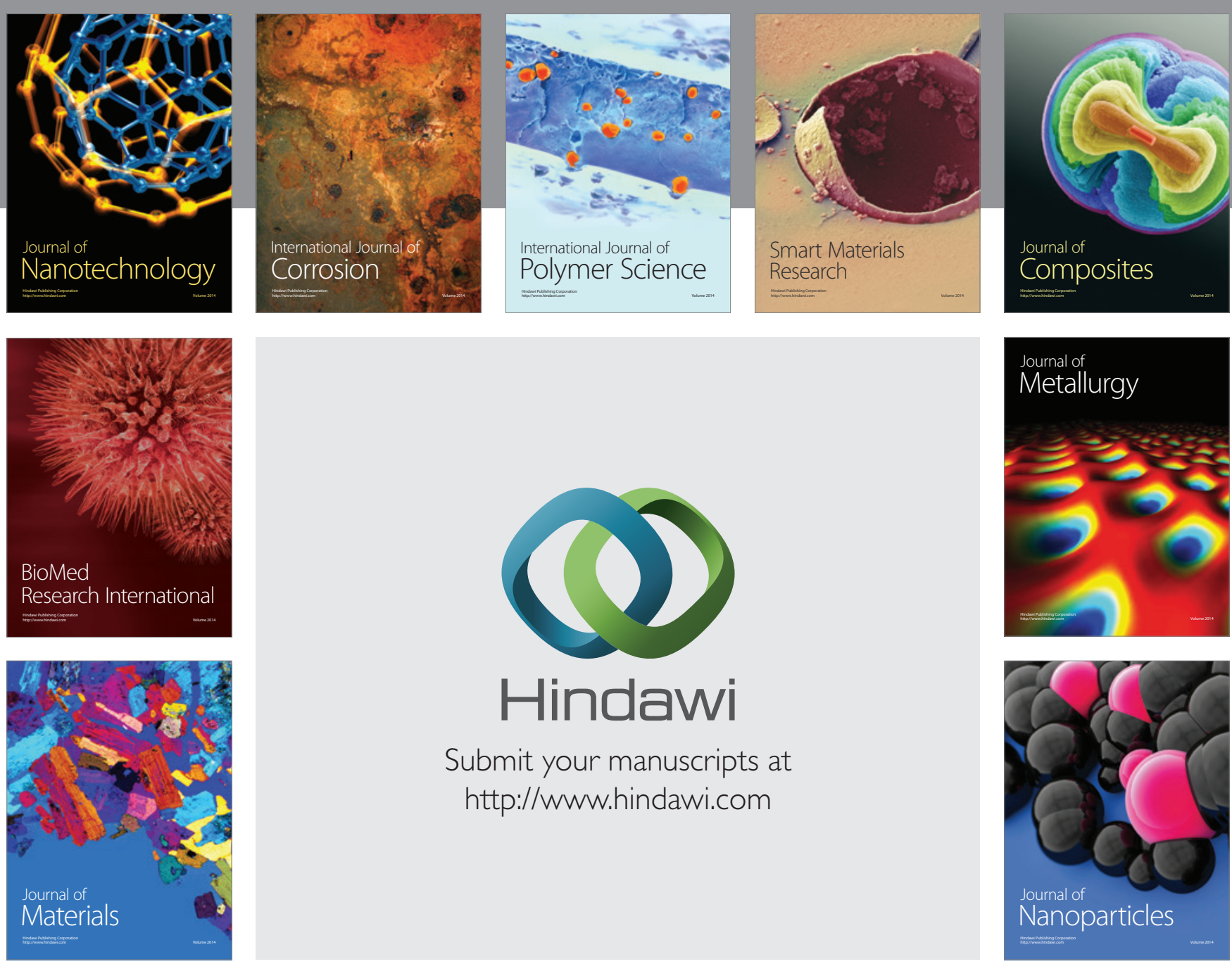

Submit your manuscripts at http://www.hindawi.com
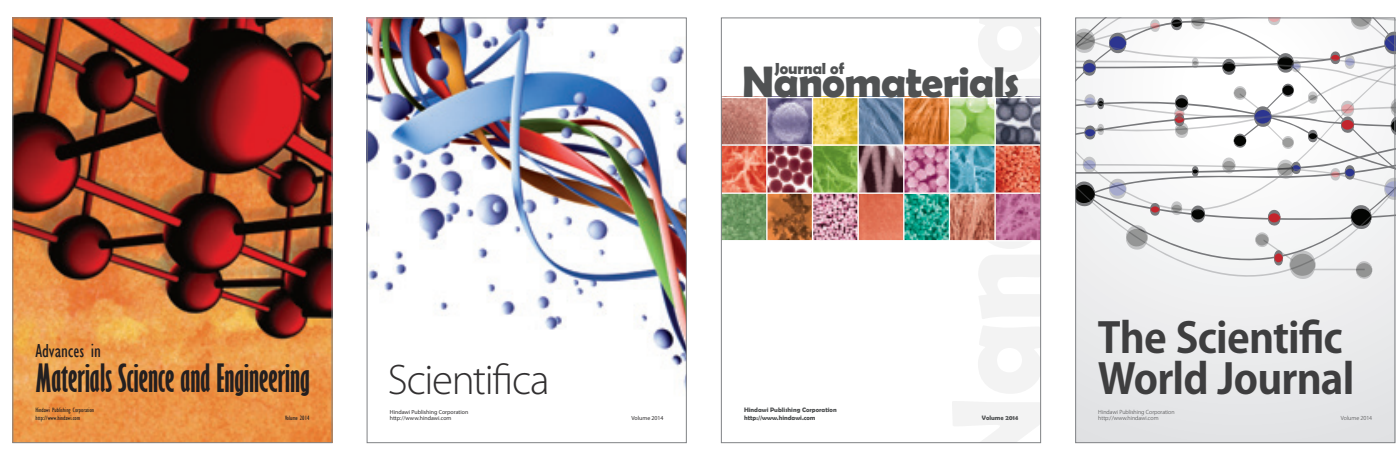

\section{The Scientific World Journal}
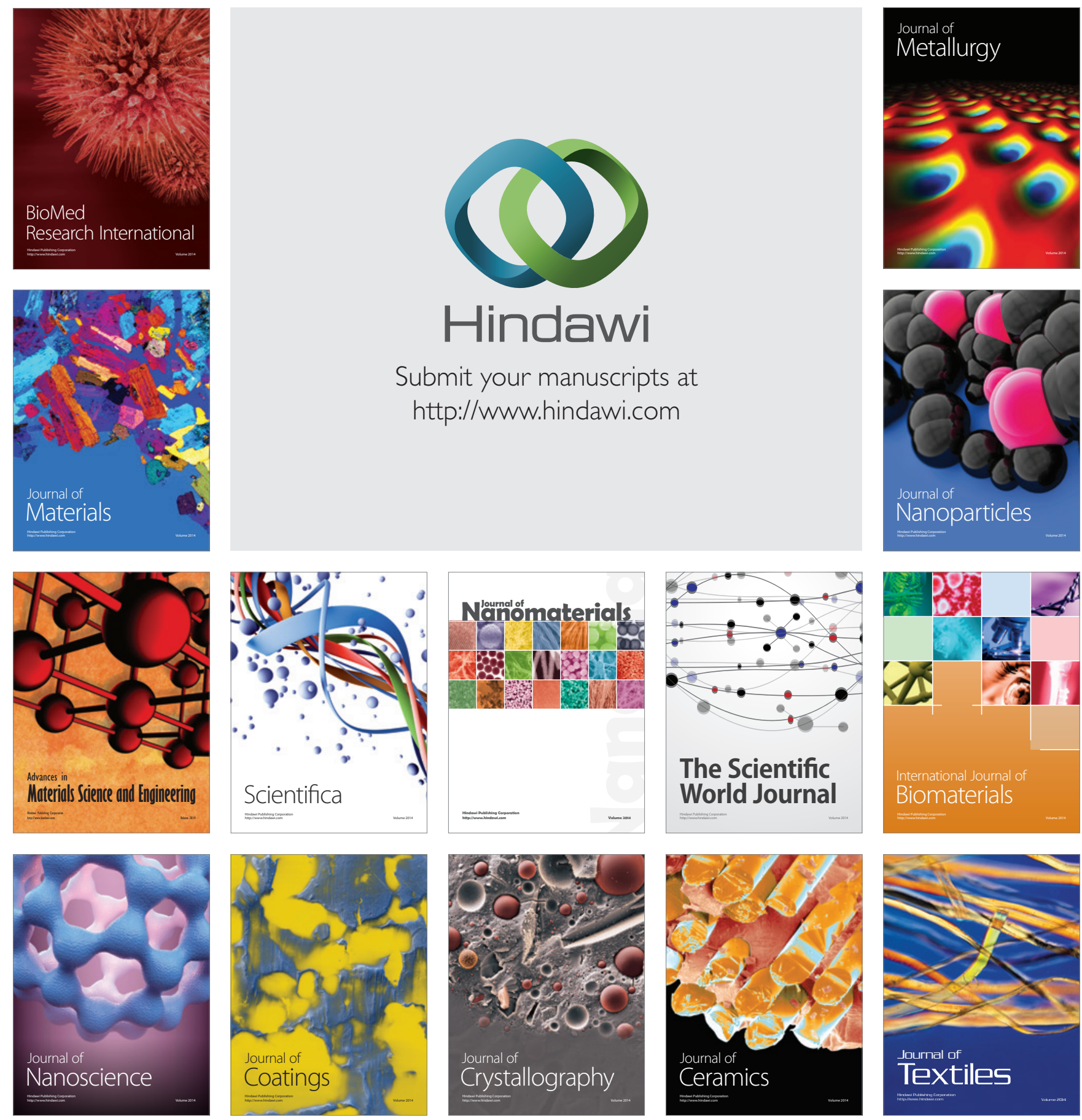